\title{
ASPEK PEMIKIRAN IBNU TAIMIYAH DI DUNIA ISLAM
}

\author{
Sefriyanti ${ }^{1^{*}}$, Mahmud Arif ${ }^{2}$ \\ UIN Sunan Kalijaga Yogyakarta \\ sefriyanti360@gmail.com*
}

Naskah diterima: 1 Agustus 2021, direvisi: 30 Agustus 2021, disetujui: 10 Desember 2021

Abstrak

Ibnu Taimiyah beliau sangat mengedepankan segala sesuatunya berdasarkan kepada Al-Qur'an dan As-sunah. Aspek pemikiran beliau mempengaruhi di dunia islam ialah dalam hal penolakan terhadap ta'wil, berpedoman dalam memahami ajaran agama dengan cara menerima pesannya dan meyakini apapun makna lahir yang tersirat dalam teks agama dan bentuk pemahaman Ibnu Taimiyah terhadap ajaran agama ini dipandang memiliki keunggulan tersendiri dalam menyongsong modernitas dengan dibuktikannya ketokohan besar yang mempengaruhi corak pemikirannya.

Kata kunci : Ibnu Taimiyah, Dunia Islam

\section{Abstract}

Ibn Taymiyya, he knows everything very well based on the Qur'an and the Sunnah. Aspects of thought that influence in the Islamic world, namely in terms of rejection of ta'wil, guided by the understanding of religion by accepting its message and any beliefs that are born from religious texts and the form of Ibn Taimiyah's understanding of religious teachings looks to have its own advantages in the song of modernity with it is proven by the great figures who influence the pattern of his thinking.

Keyword: Ibn Taymiyya, Islamic World View 


\section{PENDAHULUAN}

Ibnu Taimiyah adalah seorang yang dikenal dengan sosok yang luas pengetahuannya, luas wacananya, sangat cerdas dan mempunyai pandangan yang bijaksana. lbnu Taimiyah sangat bertaqwa kepada Allah SWT, tulus mengabdi dalam menjalankan syariat Islam. Pikirannya sangat cemerlang, pengetahuannya terhadap Alqur'an dan As Sunah sangatlah luas. Hidupnya hanya untuk menegakkan hukum Alqur'an dan Syariat nabi SAW, dan lbn Taimiyah tidak menerima hadist yang lemah untuk hujjah. Sebagian besar aktifitasnya diarahkan untuk membuka pintu ijtihad yang lama dinyatakan tertutup, memurnikan paham tauhid, dan menghidupkan pemikiran-pemikiran salaf serta menyerukan untuk kembali kepada Alqur'an dan As-sunah. Pemikiran lbnu Taimiyah bersifat tekstualitas, sehingga lbnu Taimiyah dikenal sebagai pemikir islam yang berpegang teguh pada nashnash Alqur'an.

Maka penulis akan membahas bagaimana pemikiran lbnu Taimiyah dalam dunia islam.

\section{METODE PENELITIAN}

Metode penelitian yang digunakan ialah penelitian kepustakaan (library research), penulis mengumpulkan data melalui literatur kepustakaan baik berupa buku, artikel ilmiah maupun penelitian terdahulu. Penelitian kepustakaan adalah suatu cara mengumpulkan informasi dan data dari berbagai sumber material yang ada di perpustakaan seperti buku referensi, hasil penelitian sebelumnya yang sejenis, catatan, artikel, serta berbagai jurnal yang berkaitan dengan masalah yang ingin dipecahkan.(Sari \& Asmendri, 2020).

PEMBAHASAN DAN HASIL PENELITIAN

\section{Biografi lbnu Taimiyah}

Nama asli lbnu Taimiyah adalah Taqiyuddin Abu al Abbas Ibnu Abd alHalim bin al-lmam Majduddin Abil Barakat Abd al Salam bin Muhammad bin Abdullah bin Abi Qasim Muhammad bin Khuddlarbin Ali bin Taimiyyah alHarrani al Hambali, beliau dijuluki syekhul Islam. (Bisri, 2016).

Beliau dilahirkan di kota Harran pada hari senin tanggal 10 Rabi'ul Awal tahun $661 \mathrm{H}$ bertepatan dengan tanggal 22 Januari $1263 \mathrm{M}$ (Taqiuddin, 2010). Sejak kecil, Ibnu Taimiyah berada dilingkungan keluarga berpendidikan dan ulama. Ayahnya adalah seorang ulama dimasanya, seorang ahli fatwa kenamaan dan hakim di negerinya. Ayahnya yang bernama Syihab Ad-Din 'Abd Al-Halim 
lbn Abd as-Salam (627-672 H) juga seorang penulis, khatib, serta memiliki kemampuan dalam bidang ilmu faraidh dan al-hisab yang menganut Mazhab Hanbali.

Sebagai mana ayahnya, Ibnu Taimiyah juga dikenal sebagai ulama yang bermazhab Hanbali, namun demikian tidak serta merta ia seperndapat dengan Imam Ahmad bin Hanbal.

Ibnu Taimiyah dianggap juga sebagai ulama yang tidak terikat pada madzhab atau pandangan tertentu. Baginya dalil adalah pegangannya dalam berfatwa. Karena itu ia juga menyerukan terbukanya pintu ijtihad, dan bahwa setiap orang - siapapun ia dapat diterima atau ditolak pendapatnya kecuali Rasulullah saw. Itulah sebabnya ia menegaskan, "Tidak ada seorang pun yang mengatakan bahwa kebenaran itu terbatas dalam madzhab Imam yang empat (Madzahibil Arba'ah) (lbnu Hajar, 1947).

Aspek Pemikiran lbnu Taimiyah di Dunia Islam

Ibnu Taimiyah dilahirkan sekitar abad ke 13 M., dimana dunia Islam mengalami kemunduran. Prilaku dan kehidupan masyarakat Islam sangat menyimpang dari ajaran Islam (alQur'an dan sunnah rasul), aliran dan sekte-sekte yang mengatasnamakan Islam bertambah subur, taklid buta, fanatisme mazhab, khurafat dan bid'ah mengeruhkan cakrawala pemikiran umat Islam, ditambah dengan berkembangnya pengaruh logika dan filsafat Yunani yang posisinya nyaris menggusur al-Qur'an dan as-Sunnah. Disamping gejolak intern yang terjadi dalam pemerintahan islam, dimana dunia islam juga mengalami puncak dislokasi sosial, disintegrasi politik, dan dekadensi moral yang diakibatkan oleh berbagai intervensi bangsa tar-tar, bangsa jajahan dan kaum salib sehingga kondisi tersebut semakin memburuk (Swito, 2011).

Melihat kondisi seperti ini lbnu Taimiyah tampil dengan ide pemurnian terhadap seluruh tradisi pemikiran Islam. la dikenal sebagai tokoh salaf yang pertama kali mengulirkan gagasan pemurnian terhadap ajaran Islam yang mengajak umat lslam untuk kembali kepada ajaran Islam orisinil yaitu alQur'an dan as-Sunnah serta paradigma pemikiran salaf. Aktifitas Ibnu Taimiyah dalam melancarkan misinya masih bersifat teoritis dan akademis. Hal ini disebabkan oleh kondisi yang kurang mendukung.

Meskipun demikian, khazanah pemikiran intelektul yang digagas Ibnu Taimiyah tetap menggelinding dan 
mengelaborasi dalam sejarah pemikiran dalam Islam. Pemikiran Ibnu Taimiyah kendatipun cukup tertunda, ternyata mempengaruhi gerakan pemurnian di Indonesia yang dikenal dengan gerakan tiga serangaki yaitu; Muhammadiyah, al-lrsyad dan Persis yang muncul pada abad ke $20 \mathrm{M}$. Keterpengaruhan gerakan ini terhadap wancana pemikiran lbnu Taimiyah, paling tidak gagasan untuk merujuk kembali kepada ajaran Islam murni yaitu al-Qur'an dan sunnah rasul plus paradigma pemikiran kaum salaf dan sikap anti terhadap segala bentuk kesyirikan, khurafat dan bid'ah.

Berikut implikasi beberapa aspek pemikiran lbnu Taimiyah di dunia islam diantaranya (Basyit, 2019):

\section{Penolakan Ibnu Taymiyah Terhadap Ta'wil}

Penolakan lbnu Taimiyyah terhadap metode ta'wil erat kaitannya dcngan tekadnya melakukan reformasi sosial dan keragamaan Sebagaimana yang akan dibuktikan kemudian. ta'wil menjadi semacam instrumen yang digunakan oleh para mutakallimun, filsuf dan sufi untuk memasukkan ajaran- ajaran dari berbagai sumber asing ke dalam pemahaman terhadap agama Islam. Konstruksi pemikiran lbnu Taimiyyah dalam upaya reformasinya itu dapat menjadi jelas dengan mencermati beberapa aspek yang melatarbelakanginya.(Supriadi \& Munawar, 2019). Pertama. Ibnu Taimiyyah tak dipengaruhi oleh siapapun kecuali oleh kaum muslim terdahulu yang saleh (al-salaf alshalihin) dalam membentuk skema reformasinya. itulah sebabnya gerakan reformasinya sering disebut sebagai gerakan salafi. Motonya adalah kembali kepada al-Qur'an dan Sunnah.

Kedua, Ibnu Taimiyyah menentang semua bentuk inovasi dalam agama (bid'ah). Dia yakin bahwa lslam telah dirusak oleh sufisme, pantheisme, theologi, filsafat dan semua bentuk kepercayaan takhayul. Oleh karena lbn Taimiyyah kemudian menulis berbagai karya untuk menentang kaum sufi, mu'akallimun dan para filsuf Muslim yang bertaklid kepada Aristoteles.

Ketiga, reformasi lbnu Taimiyah juga berporos pada penolakan terhadap klaim bahwa akal dikhususkan untuk memahami prinsip-prinsip agama yang menyiratkan bahwa akal lebih terlama dari pada wahyu karena akal dianggap memiliki hak, jika memang bukan kewajiban, untuk menafsirkan ambiguitas wahyu (ayat-ayat mutasyabihat). Menurut lbnu Taimiyyah, wahyu lebih utama dari pada akal, sebab ajaran Tuhan adalah supra-rasional. Dia yakin bahwa tak ada 
pertentangan antara agama dan akal. Agama senantiasa logis, atau bahwa nash (teks agama) dan aql (akal manusia) merupakan dua aspek yang berbeda dari kebenaran yang sama.

Kritik lbnu Taimiyyah terhadap metode ta'wil dilandasi oleh keyakinannya bahwa melalui fitrah, kesadaran manusia mengenai Tuhan menjadi sebuah kebenaran aksiomatik (self- evident truth, al-haqiqah albadihiyyah) dan pengetahuan yang benar, sehingga lbnu Taimiyah mengajak umat Islam bersedia back to basics (kembali ke dasar ajaran, alQur'an dan hadis) .

\section{Pandangan lbnu Taimiyah tentang “ Al} Haqiqoh fil a'yan la fil adzhan"

Dalam kitab Akidatul Wasitiyah karangan lbnu Timiyah menjelaskan dalam lafal Al Haqiqoh fil a'yan la fil adzhan ialah : Bahwa dalam lafal "Fil A'yan “ tidak diperolehkan memberikan ta'wil/ menakwilkan sifat-sifat Allah baik dalam Alqur'an maupun Al-Hadist dengan alasan bahwa lbnu Taimiyah ingin meluruskan makna yang sebenarnya, maka tidak boleh menakwili antara Allah dengan mahluknya, sedangkan menurut lbnu Taimiyah jika golongan yang menakwili Allah dengan mahluknya maka lbnu Taimiyah menyebutnya sebagai golongan
Mujasimah (Taimiyah, 1903).

\section{Berpedoman dengan memahami ajaran agama dengan cara menerima pesannya dan meyakini apapun makna lahir yang tersirat dalam teks agama.}

Ibn Taymiyyah menyarankan untuk memahami ajaran agama dengan cara menerima pesannya dan meyakini apapun makna lahir yang tersirat di dalam teks agama. Ibn Taymiyyah mengawali argumennya dengan prinsip bahwa Tuhan mengetahui kebenaran jauh lebih baik daripada manusia dan mengetahui secara jauh lebih baik mengenai cara untuk mengungkapkan kebenaran tersebut. Firman llahi di dalam Al-Qur'an harus dipahami persis seperti yang diungkapkan. Makna kata yang langsung terlintas di dalam pikiran harus dipandang sebagai indikasi pemahaman yang benar terhadap kata itu. Dalam konteks ini, Ibn Taymiyyah memberikan apresiasi terhadap jargon al-Syafi'i dalam bidang Ushul Figh bahwa kecepatan pemahaman merupakan tanda kebenaran. Yang bertentangan dengan prinsip ini adalah konsep ta'wîl para filsuf Muslim yang mengambil bentuk penafsiran yang jauh (al-tafsîr al-baî̀d). 
3. Bentuk pemahaman lbnu Taimiyah

\begin{tabular}{lll} 
terhadap ajaran agama ini & \multicolumn{1}{c}{ ana } \\
dipandang & memiliki keunggulan \\
tersendiri & dalam menyongsong
\end{tabular}

Adapun Pengaruh pemikiran

lbn Taymiyyah dapat dicerminkan oleh seberapa besar ketokohan intelektual para pengikutnya ialah sebagai berikut :

Muhammad ibn- Abd alWahhab pendiri wahabisme, dengan gerakannya untuk memurnikan ajaran Islam, tidaklah berkeinginan mengubah ajaran Islam dengan penafsiran baru terhadap wahyu. Tetapi membawa misi untuk memberantas bid'ah, khufarat, dan takhyul yang masuk ke dalam ajaran Islam. Muhammad ibn- Abd alWahhab bermaksud mengajak umat Islam agar kembali kepada ajaran Islam yang murni yakni ajaran Islam sebagaimana yang dianut dan dipraktekkan di zaman Nabi saw, sahabat serta tabiin, yaitu sampai abad ke-3 Hijrah.

Pengaruh pemikiran lbn Taymiyyah terhadap Muhammad Abduh tercermin melalui seruan Muhammad Abduh untuk kembali kepada Al-Qur'an dan Sunnah, dan sikap anti taklid demi melepaskan diri dari kejumudan. Abduh ingin membebaskan Mesir berada dari kebodohan dan kemunduran selama berabad-abad. Dia ingin meruntuhkan paham berbagai mazhab yang kaku lalu masuk ke alam kebebasan berpikir agar dapat menyelaraskan keyakinan keagamaan dengan kebutuhan zaman modern. Muhammad Abduh menonjolkan paham lbn Taymiyyah yang menyatakan bahwa ajaran Islam meliputi ibadah dan Muamalat. Menurut Abduh, ajaran Islam yang terdapat dalam alQur'an dan hadis mengenai ibadah bersifat tegas, jelas dan terperinci. Sedangkan ajaran-ajaran mengenai kehidupan sosial hanya mencakup prinsip-prinsip yang bersifat umum. Dan juga melihat bahwa ajaran yang terdapat dalam al-Qur'an dan hadis mengenai kemasyarakatan hanya sedikit jumlahnya. Abduh berpendapat bahwa semua itu dapat disesuaikan dengan tuntutan zaman.

Nurcholis Madjid, pemikiran Ibn Taymiyyah menjadi sesuatu yang doktrinal bagi banyak sekali gerakan pembaruan Islam zaman modern, baik yang fundamentalistik maupun yang liberal. Selain itu, kritik lbn Taymiyyah terhadap Kalam dan Falsafah dilakukan dengan kompetensi keilmuan Islam yang helenistik.

\section{KESIMPULAN}

lbnu Taimiyah beliau sangat mengedepankan segala sesuatunya berdasarkan kepada Al-Qur'an dan As- 
sunah. Aspek pemikiran beliau mempengaruhi di dunia islam ialah dalam hal penolakan terhadap ta'wil, berpedoman dalam memahami ajaran agama dengan cara menerima pesannya dan meyakini apapun makna lahir yang tersirat dalam teks agama dan bentuk pemahaman Ibnu Taimiyah terhadap ajaran agama ini dipandang memiliki keunggulan tersendiri dalam menyongsong modernitas dengan dibuktikannya ketokohan yang mempengaruhi corak pemikirannya.

\section{DAFTAR PUSTAKA}

Basyit, A. (2019). PENGARUH PEMIKIRAN IBN TAYMIYYAH DI DUNIA ISLAM. Rausyan Fikr : Jurnal Pemikiran Dan Pencerahan, 15(2).

Bisri, T. (2016). PENGARUH

PEMIKIRAN IBNU TAIMIYAH TERHADAP PEMIKIRAN IBNU ABDULWAHHAB TENTANG SYIRIK (STUDI KOMPARASI). Jurnal Dirasat Islamiyah Al Majaalis, 3(2).

Ibnu Hajar, A.-'Asqanaly. (1947). AlDurar al-Kaminah fi A'yan al-Mi'ah al-Tsaminah. Dar al-Ma'arif.

Sari, M., \& Asmendri. (2020). Penelitian Kepustakaan (Library Research) dalam Penelitian Pendidikan IPA.
Penelitian Kepustakaan (Library

Research) Dalam Penelitian

Pendidikan IPA, 6(1).

https://ejournal.uinib.ac.id/jurnal/in dex.php/naturalscience/article/view/ 1555/1159

Supriadi, \& Munawar. (2019). ANALISIS PANDANGAN IBNU TAIMIYAH TENTANG KEDUDUKAN TA'WIL DALAM MEMAHAMI AL-QUR'AN. Asy-Syukriyyah, 20(1).

Swito, F. (2011). Peran ibnu taimiyah dalam pemurnian aqidah islamiyah. Universitas Islam Negeri Syarif Hidayatullah.

Taimiyah, 1. (1903). Al-Aqidatul Wasithiyah (cet I).

Taqiuddin, A. (2010). Pemikiran Tasawuf Ibnu Taimiyah. El-Hikam : JURNAL Pendidikan Dan Kajian Keislaman, $3(2)$. 
p-ISSN 2685-8401 e-ISSN 2685-7502

(Halaman sengaja dikosongkan) 